Jurnal Pujangga Volume 6, Nomor 2, Desember 2020

ISSN P 2443-1478

ISSN E 2443-148

\title{
ANALISIS NILAI PENDIDIKAN DALAM NOVEL RANAH TIGA WARNA KARYA A. FUADI
}

\author{
Endang Sulistyaniningsih \\ Universitas Indraprasta PGRI \\ 085777239152 \\ esulistyaniningsih@gmail.com
}
Fatimah
Universitas Indraprasta PGRI
087784814086
fatimahifat4@gmail.com

As'ad

Universitas Indraprasta PGRI

085770747855

asadptnu@gmail.com

Received August 7,2020; Revised August 12, 2020; Approved Oct 15, 2020

\begin{abstract}
ABSTRAK
Penelitian ini menganalisis nilai pendidikan dalam novel Ranah 3 Warna karya Ahmad Fuadi yang meliputi nilai pendidikan agama, moral, adat/budaya, dan sosial. Tujuan penelitian ini adalah untuk mendeskripsikan nilai pendidikan novel Ranah 3 Warna karya Ahmad Fuadi. Penelitian ini merupakan penelitian deskriptif kualitatif. Data yang digunakan berupa kutipan langsung maupun tidak langsung dari teks novel Ranah 3 Warna karya Ahmad Fuadi. Teknik pengumpulan data dalam penelitian ini adalah studi pustaka dan observasi. Instrumen penelitian ini adalah peneliti sendiri. Analisis data dilakukan dengan metode analisis isi. Penyajian hasil analisis menggunakan teknik penyajian informal. Hasil penelitian ini disimpulkan bahwa tema novel Ranah 3 Warna karya Ahmad Fuadi adalah perjuangan Alif demi meraih impian dan cita-cita dengan segala keterbatasan. Nilai pendidikan dalam novel Ranah 3 Warna ada empat, yaitu nilai pendidikan agama meliputi beribadah, berdoa, bersyukur, tawakal, ikhlas, dan sabar, nilai pendidikan moral meliputi tekad kuat, pantang menyerah, sungguh-sungguh, kerja keras, rajin belajar, mampu mengendalikan diri, disiplin, jujur, tanggung jawab, kreatif, nasionalisme, percaya diri, dan prasangka baik, nilai pendidikan adat/budaya meliputi melestarikan kesenian tradisional dan melestarikan budaya berpantun, nilai pendidikan sosial meliputi tolong-menolong, berbakti kepada orang tua, setia kawan, persahabatan, kasih sayang, memberi semangat, dermawan, musyawarah, dan rela berkorban.
\end{abstract}

Kata Kunci: nilai pendidikan, karya sastra, novel

\begin{abstract}
This study analyze the value of education in the novel Ranah 3 Warna Ahmad Fuadi's work which includes the value of religious, moral, custom/cultural, and social education. Th e purpose of this study is to describe the educational value of Ranah 3 Color novel by Ahmad Fuadi. This research is a qualitative descriptive study. The data used in the form of direct or indirect quotations from the text of the Ranah 3 Color novel by Ahmad Fuadi. Data collection techniques in this research are literature study and observation. The research instrument is the researcher himself. Data analysis was performed using the content analysis method. Presentation of analysis results using informal presentation techniques. The results of this study concluded that the theme of the Ranah 3 Color novel by Ahmad Fuadi was Alif's struggle to achieve dreams and ideals with all limitations. There are four educational values in the
\end{abstract}


ISSN P 2443-1478

ISSN E 2443-148

Ranah 3 Color novel, namely the value of religious education including worship, prayer, gratitude, trust, sincerity, and patience, the value of moral education includes determination, unyielding, earnestly, hard work, diligent learning, being able to control self, discipline, honest, responsibility, creative, nationalism, self-confidence, and good prejudice, the value of traditional / cultural education includes preserving traditional arts and preserving the culture of rhyming, the value of social education includes help, helping, serving parents, loyal friends, friendship, compassion, encouragement, generosity, deliberation, and willing to sacrifice.

Keywords: educational values, novel

\section{PENDAHULUAN}

\section{Latar Belakang}

Globalisasi adalah suatu proses, yakni antarindividu, antarkelompok, dan antarnegara saling berinteraksi, bergantung, terkait, dan saling mempengaruhi satu sama lain yang melintasi batas negara. Globalisasi mempengaruhi hampir semua aspek yang ada di masyarakat, termasuk di antaranya aspek budaya.

Nilai pendidikan sangat erat hubungannya dengan karya sastra dalam hal ini novel, yang selalu mengungkapkan nilai pendidikan misalnya nilai pendidikan moral, agama, sosial, maupun estetis (keindahan). Dengan adanya berbagai wawasan yang dikandung dalam karya sastra khususnya novel, hal ini menunjukkan bahwa pada dasarnya suatu karya sastra akan selalu mengandung bermacam-macam nilai kehidupan yang akan sangat bermanfaat bagi pembaca.

Karya sastra adalah produk dari budaya sebagai sebuah karya kreatif yang lahir dari pemikiran dan pengalaman pengarangnya sering mencerminkan pandangannya dalam melihat sebuah kehidupan. Pengalaman tersebut ditulis sebagaimana adanya untuk dimaknai sebagai bentuk implementasi baik dari pengungkapan pikiran maupun perasaan yang ada pada diri manusia. Sebagai sebuah karya kreatif, karya sastra tidak hanya mengandung unsur keindahan, melainkan karya sastra sering mencerminkan nilai-nilai moral dalam kehidupan bermasyarakat.

Salah satu bentuk karya sastra adalah Novel. Novel adalah karangan prosa yang lebih panjang dari cerita pendek dan menceritakan kehidupan seseorang dengan lebih mendalam dengan menggunakan bahasa sehari-hari serta banyak membahas aspek kehidupan manusia. Hal ini mengacu pada pendapat Santoso dan Wahyuningtyas (2010: 46), yang menjelaskan, "Kata novel berasal dari bahasa latin novellas, yang terbentuk dari kata novus yang berarti baru atau new dalam bahasa Inggis. Karena novel adalah bentuk karya sastra yang datang dari karya sastra lainnya seperti puisi dan drama. 
Jurnal Pujangga Volume 6, Nomor 2, Desember 2020

ISSN P 2443-1478

ISSN E 2443-148

Sedangkan menurut Sumarjo dalam Santosa dan Wahyuningtyas (2010: 47), "Novel diartikan sebagai produk masyarakat. Novel berada di masyarakat karena novel dibentuk oleh anggota masyarakat berdasarkan desakan-desakan emosional atau rasional dalam masyarakat". Sedangkan menurut Kamus Besar Bahasa Indonesia 1996 dalam Siswanto (2008: 141), Novel diartikan sebagai "Karangan prosa yang panjang, mengandung rangkaian cerita kehidupan seseorang dengan orang-orang disekelilingnya dengan menonjolkan watak dan sifat pelaku.

Secara etimologis, sastra merupakan alat untuk mendidik (Ratna, 2009:360). Secara keseluruhan karya sastra merupakan sarana-sarana etika. Jadi, antara pendidikan dan karya sastra (novel) adalah dua hal yang saling berkaitan. Pendidikan pada hakikatnya merupakan upaya membantu peserta didik untuk menyadari nilai-nilai yang dimilikinya dan berupaya memfasilitasi mereka agar terbuka wawasan dan perasaannya untuk memiliki dan meyakini nilai yang lebih hakiki, lebih tahan lama, dan merupakan kebenaran yang dihormati dan diyakini secara sahih sebagai manusia yang beradab (Setiadi, 2010:120). Pendidikan tidak hanya mengantar peserta didik pada nilai dirinya, tetapi harus membimbing mereka untuk meyakin i nilai yan paling hakiki, terdalam, dan paling dasar.

Dengan demikian, nilai pendidikan dalam sastra merupakan segala sesuatu yang berguna bagi kehidupan manusia yang diperoleh melalui proses pengubahan sikap dan tata laku dalam upaya mendewasakan diri manusia melalui upaya pengajaran. Apabila dihubungkan dengan eksistensi dan kehidupan manusia, nilai-nilai pendidikan diarahkan pada pembentukan pribadi manusia sebagai makhluk individu, sosial, religius, dan berbudaya. Sastra sangat berperan penting sebagai media dalam pentransformasian sebuah nilai termasuk halnya nilai pendidikan.

Karya sastra diciptakan bukan sekadar untuk dinikmati, tetapi untuk dipahami dan diambil manfaatnya. Karya sastra tidak sekadar benda mati yang tidak berarti, tetapi di dalamnya termuat suatu ajaran berupa nilai-nilai hidup dan pesan-pesan luhur yang mampu menambah wawasan manusia dalam memahami kehidupan. Dalam karya sastra, berbagai nilai hidup dihadirkan karena hal ini merupakan hal positif yang mampu mendidik manusia sehingga manusia mencapai hidup yang lebih baik sebagai makhluk yang dikaruniai oleh akal, pikiran, dan perasaan.

Ada beberapa nilai pendidikan yang dapat diperoleh dari sebuah cerita (dalam hal ini novel). Nilai pendidikan itu di antaranya adalah yang berhubungan dengan agama, moral, budaya, dan sosial. 1) Nilai Pendidikan Agama adalah hal yang mutlak dalam kehidupan manusia sehingga dari pendidikan ini diharapkan dapat terbentuk manusia religius. Mangunwijaya (dalam Nurgiyantoro, 
Jurnal Pujangga Volume 6, Nomor 2, Desember 2020

ISSN P 2443-1478

ISSN E 2443-148

2010: 327) menyatakan bahwa agama lebih menunjukkan pada kelembagaan kebaktian kepada Tuhan hukum-hukum resmi. Religius, di pihak lain melihat aspek yang di lubuk hati, riak getar nurani, totalitas ke dalam pribadi manusia. Dengan demikian, religius bersifat mengatasi lebih dalam dan lebih luas dari agama yang tampak formal dan resmi. Nilai pendidikan agama dalam karya sastra sebagian menyangkut moral, etika, dan kewajiban. Hal ini menunjukkan adanya sifat edukatif (Nurgiyantoro, 2010: 317). 2)

Nilai Pendidikan Moral Moral merupakan laku perbuatan manusia dipandang dari nilai-nilai baik dan buruk, benar dan salah, dan berdasarkan adat kebiasaan di mana individu berada (Nurgiyantoro, 2010: 319). Nilai moral yang terkandung dalam karya sastra bertujuan untuk mendidik manusia agar mengenal nilai-nilai etika dan budi pekerti. Nilai pendidikan moral menunjukkan peraturanperaturan tingkah laku dan adat istiadat seorang individu dari suatu kelompok yang meliputi perilaku, tata karma yang menjunjung budi pekerti dan nilai susila. 3) Nilai Pendidikan Adat/Budaya Koentjaraningrat (1993: 18) mengemukakan bahwa sistem nilai budaya terdiri atas konsepsi-konsepsi yang hidup dalam alam pikiran sebagian besar warga masyarakat, mengenai hal-hal yang harus mereka anggap amat bernilai dalam hidup. Suatu sistem nilai budaya biasanya berfungsi sebagai pedoman tertinggi bagi kelakuan manusia. Nilai-nilai budaya yang terkandung di dalam cerita dapat diketahui melalui penelaahan terhadap karakteristik dan perilaku tokoh-tokoh dalam cerita. 4) Nilai Pendidikan Sosial Kata "sosial" berarti hal-hal yang berkenaan dengan masyarakat/ kepentingan umum. Nilai sosial merupakan hikmah yang dapat diambil dari perilaku sosial dan tata cara hidup sosial. Perilaku sosial berupa sikap seseorang terhadap peristiwa yang terjadi di sekitarnya yang ada hubungannya dengan orang lain, cara berpikir, dan hubungan sosial bermasyarakat antarindividu.

\section{Rumasan Masalah}

Berdasarkan latar belakang masalah yang ada, maka peneliti memfokuskan rumusan masalah bagaimana nilai pendidikan yang terdapat pada novel Ranah 3 Warna karya Ahmad Fuadi?

\section{Tujuan Penelitian}

Mendeskripsikan nilai pendidikan yang terdapat pada novel Ranah 3 Warna karya Ahmad Fuadi. 
ISSN P 2443-1478

ISSN E 2443-148

\section{Tinjauan Pustaka}

Agar sebuah penelitian memiliki keasliannya perlu adanya tinjauan pustaka. Tinjauan pustaka berfungsi untuk memberikan pemaparan tentang penelitian dan analisis sebelumnya yang telah dilakukan. Tinjauan terhadap hasil penelitian dan analisis sebelumnya ini akan dipaparkan yang berkaitan dengan novel Ranah 3 Warna karya ahmad Fuadi.

Beberapa hasil penelitian yang telah dipublikasikan antara lain penelitian Siti Zuhroh (2010) berjudul "Nilai-Nilai Pendidikan Novel Para Priyayi Karya Umar Kayam”. Permasalahan yang dibahas dalam penelitian ini meliputi sruktur novel dan nilai-nilai pendidikan dalam novel Para Priyayi. Nilai-nilai pendidikan yang terkandung dalam novel ini meliputi nilai sosial tercermin dalam tata cara hidup bermasyarakat, nilai religius tercermin dalam kegiatan religi dan kegiatan yang mencakup keseluruhan rasa pribadi manusia dalam mengakui adanya agama, nilai moral tercermin dalam tingkah laku dan perbuatan manusia yang bersumber pada kaidah hukum, adat, kebiasaan, agama, dan lain-lain, nilai filosofi terutama pada sebuah perenungan kehidupan, dan nilai budaya berkaitan dengan adat istiadat, norma, tradisi dan kebiasaan yang terdapat dalam kehidupan masyarakat. Penelitian yang telah dilakukan oleh Siti Zuhroh ini memiliki persamaan dan perbedaan dengan penelitian yang penulis lakukan. Persamaannya, keduanya membahas nilai pendidikan yang terdapat pada novel yang dianalisis. Perbedaannya, Siti Zuhroh hanya menganalisis struktur dan nilai pendidikan yang terdapat pada novel tanpa memberi gambaran tentang bagaimana kesesuaian novel tersebut sebagai bahan pembelajaran sastra di SMA, sedangkan penulis menganalisis nilai-nilai pendidikan dalam novel saja. Perbedaan lainnya terletak pada objek penelitian. Objek penelitian pada skripsi Siti Zuhroh yaitu novel Para Priyayi karya Umar Kayam, sedangkan objek penelitian yang penulis teliti yaitu novel Ranah 3 Warna karya Ahmad Fuadi.

Penelitian Muntolib (2010) berjudul “Aspek Edukatif dan Religius Kumpulan Cerpen Gres Karya Putu Wijaya dan Kaitannya dengan Pembelajaran Sastra di SMA". Penelitian ini menyajikan penyimpangan dan kebaruan, aspek edukatif dan aspek religius dalam cerpen Gres. Cerpen ini memiliki beberapa nilai pendidikan yaitu pendidikan mental, pendidikan kesusilaan, pendidikan kesosialan, dan pendidikan kedisiplinan, sedangkan aspek religius dalam cerpen Gres mencakup pendekatan terhadap berbagai macam keyakinan dalam kehidupan beragama, antara lain Islam, Kristen, Hindu yang dianut oleh masyarakat pada umumnya. Penelitian ini memiliki persamaan dan perbedaan dengan penelitian yang penulis lakukan. Persamaannya, keduanya menganalisis nilai pendidikan, termasuk di dalamnya yaitu nilai religius/agama. Perbedaannya 
Jurnal Pujangga Volume 6, Nomor 2, Desember 2020

ISSN P 2443-1478

ISSN E 2443-148

terletak pada objek penelitian yang diambil. Penelitian Muntolib mengambil objek penelitian yaitu cerpen Gres karya Putu Wijaya, sedangkan objek penelitian yang penulis ambil yaitu novel Ranah 3 Warna karya Ahmad Fuadi. Oleh karena itu, penulis merasa perlu untuk menelitinya agar memperlengkap dan memperdalam penelitian yang telah ada.

\section{METODE PENELITIAN}

Penelitian ini termasuk jenis penelitian deskriptif kualitatif artinya data yang dideskripsikan merupakan data kualitatif yang berakar pada latar alamiah yang mengandalkan manusia sebagai alat penelitian (Arikunto, 2006:20). Penelitian ini hanya mendes-kripsikan nilai pendidikan dalam novel Ranah 3 Warna karya Ahmad Fuadi.

Objek penelitian ini adalah nilai pendidikan pada teks novel Ranah 3 Warna karya Ahmad Fuadi yang diterbitkan oleh Gramedia Pustaka Utama Jakarta, cetakan kedua tahun 2011, setebal 486 halaman, sebagai sumber primer.

\section{HASIL DAN PEMBAHASAN}

\section{Nilai Pendidikan dalam novel Ranah 3 Warna}

Nilai pendidikan novel Ranah 3 Warna karya Ahmad Fuadi yang terdiri atas nilai pendidikan agama, moral, adat/budaya, dan social, adalah sebagai berikut:

a. Nilai pendidikan Agama di dalam novel

Ranah 3 Warna karya Ahmad Fuadi. Unsur pendidikan yang berhubungan dengan ibadah:

"Selepas salat Subuh, dengan berkelumun sarung, aku dan Ayah telah berdiri di pinggir jalan aspal satu-satunya di kampungku. Sebentarsebentar aku berjingkat dan memanjangkan leher untuk melihat ujung tikungan, menunggu bus Harmonis paling pagi turun dari Bukit-tinggi. Bis ini membawa surat kabar Haluan yang memuat pengumuman UMPTN hari ini." (R3W/2011/28)

Unsur pendidikan yang berhubungan dengan Doa:

"Duhai Tuhanku, inilah janjiku pada diriku.

Mohon Engkau saksikan dan tunjukilah aku ke jalan yang benar," bisikku sambil menempelkan janji ini di dinding kamarku." (R3W/2011/108) "Nak, sudah wa'ang patuhi perintah Amak untuk sekolah agama, kini pergilah menuntut ilmu sesuai keinginanmu. Niatkanlah untuk ibadah, insya Allah selalu dimudahkanNya. Setiap bersimpuh setelah salat, Amak selalu berdoa untuk wa’ang," kata Amak." (R3W/2011/41)

Unsur pendidikan yang berhubungan dengan Rasa Syukur: 
"Walau bukan Teknik Penerbangan ITB, seperti impian awalku, Jurusan Hubungan Internasional adalah sebuah rezeki besar bagi diriku. Beralaskan koran pengumuman, aku sujud syukur untuk keajaiban ini. Keajaiban tekad dan usaha, keajaiban restu orang tua, keajaiban doa. Di sebelahku, Ayah juga sujud lama sekali. (R3W/2011/30)

Unsur pendidikan yang berhubungan dengan Rasa Berserah Diri:

"Aku coba menghibur diriku. Toh aku telah melakukan segenap upaya, di atas rata-rata. Telah pula aku sempurnakan kerja keras dengan doa. Sekarang tinggal aku serahkan kepada putusan Tuhan.” (R3W/2011/28)

Unsur pendidikan yang berhubungan dengan Rasa Tulus Ikhlas:

“Apa gunanya masa muda kalau tidak untuk memper-juangkan cita-cita besar dan membalas budi orang tua? Biarlah tulang mudaku remuk dan badanku susut. Aku ikhlas mengorbankan masa muda yang indah seperti yang dinikmati kawan-kawanku." (R3W/2011/117) "Akhirnya aku sampai pada suatu kesimpulan yang selalu diajarkan di PM: ikhlaskan. Itulah satu-satunya cara agar aku bisa menentramkan hati dan berdamai dengan kenyataan ini. Aku ikhlaskan mereka bertunangan. Aku telah bersabar, telah mengamalkan man shabara zhafira, tapi hanya Tuhan yang tahu apa yang terbaik buat aku, buat Randai, dan buat Raisa. Pelan-pelan, semuanya terasa makin masuk akal." (R3W/2011/461)

Unsur pendidikan yang berhubungan dengan Rasa Sabar:

"Dan beliau selalu tahu nasihat apa yang sedang aku butuhkan. Di kondisi terpuruk ini aku disuruh Amak memperbanyak sabar. Betapa butuhnya aku nasihat seperti ini. Suara penyiar KLCBS kembali terngiang di kupingku. "Siapa yang bersabar akan beruntung." Sesuatu tibatiba berkelebat di ingatanku. Hei, aku tahu itu. Aku bahkan pernah tahu versi asli kata mutiara dari Arab itu. Bunyinya: Man shabara zhafira.” (R3W/2011/130)

b. Nilai pendidikan Moral di dalam novel Ranah 3 Warna karya Ahmad Fuadi. Data kutipan yang ada dalam nilai pendidikan moral yan mengarah ke tekad yang kuat adalah sebagai berikut:

"Jangankan setahun, tiga tahun pun akan aden lakukan demi mencapai cita- cita. Kalau tidak mau menolong, aden akan tolong diri sendiri." (2011:10)

"Man Jadda Wajadda! Mantra ini menjadi motivasiku kalau sedang kehilangan semangat.bahkan aku teriakkan kepada diriku,setiap aku merasa semangatku melorot"'(R3W/201/12)

Data kutipan yang ada dalam nilai pendidikan moral yan mengarah ke jiwa pantang menyerah adalah sebagai berikut: 
"Bahkan aku teriakkan kepada diriku, setiap aku merasa semangatku melorot. Aku paksa diriku lebih kuat lagi. Aku lebihkan usaha. Aku lanjutkan jalanku beberapa halaman lagi, beberapa soal lagi, beberapa menit lagi. Going the extra miles. I'malu fauqa ma 'amilu. Berusaha di atas rata-rata orang lain. (R3W/2011/12) "Terima kasih, Bu, tapi saya punya banyak bakat, selain menyanyi." "Sorry. Your time is up. Waktu Anda habis." "Ibu, ini menentukan masa depan saya. Mohon beri kesempatan sekali lagi, memperlihatkan apa yang saya bisa sumbangkan untuk program pertukaran penting ini," kataku dengan nada paling mengiba-iba yang aku bisa." (R3W/2011/204)

Data kutipan yang ada dalam nilai pendidikan moral yan memiliki kemauan untuk berniat bersungguh-sungguh adalah sebagai berikut:

"Mungkin sudah waktunya aku disapih, berhenti meminta uang ke Amak. Aku genggam foto keluarga erat-erat, sampai hampir remuk. Aku berjanji pada diri sendiri akan membiayai diri sendiri selama di Bandung. Bukan cuma membiayai diri sendiri, tapi kalau bisa juga mengirimi Amak uang setiap bulan. Sejujurnya aku tidak tahu bagaimana caranya. Tapi ada sebersit kepercayaan tumbuh di pedalaman hatiku kalau aku mau berniat bersungguhsungguh, insya Allah bisa.” (R3W/2011/101)

Data kutipan yang ada dalam nilai pendidikan moral yang memiliki kemauan untuk bersemangat bekerja keras adalah sebagai berikut:

"Sejak itu, selain menawarkan produk dari Wira, aku sekarang juga menjajakan kain dari Bukittinggi ini ke berbagai acara ibu-ibu. Ada arisan, pertemuan keluarga, sampai rapat Persit Kartika Chandra Kirana di Seskoad, Buah Batu. Bahkan dengan menelan bulat-bulat gengsi$\mathrm{ku}$, 5. 6. 7. 8. 9. jualan pun aku bawa masuk sampai ke ruang dosen dan ruang kuliahku. Hanya rumah kos Raisa yang belum aku datangi untuk berjualan." (R3W/2011/116) "Aku kini sudah punya beberapa naskah tulisan opini yang menurut Bang Togar sudah layak untuk dikirim ke koran lokal. Tentu semuanya telah melalui proses coreng-moreng spidol merah yang kejam." (R3W/2011/145)

Data kutipan yang ada dalam nilai pendidikan moral yang memiliki semangat rajin belajar adalah sebagai berikut:

"Sambil selonjoran di kamar, beberapa jam aku habiskan mencorat-coret konsep dasar tulisanku. Beberapa buku referensi dari perpustakaan bertaburan di depanku. Tulisanku berisi tinjauan historis upaya menuju Palestina yang merdeka. Randai yang sedang mengerjakan tugas terheranheran melihat aku menulis awut-awutan seperti dikejar setan. Menjelang tengah malam, 
ISSN P 2443-1478

ISSN E 2443-148

aku menghela napas, naskah tulisan tangan selesai juga. Tinggal mengetik saja." (R3W, 2011:

69) "Akhirnya aku memilih untuk ikhlas saja, walau diperla-kukan dengan keras. Hari ini aku sibuk sekali karena harus memperbaiki naskah, mengetik ulang, mengantar, dan dicoret Bang Togar lagi. Sampai berulang-ulang." (R3W/2011/76)

Data kutipan yang ada dalam nilai pendidikan moral yang memiliki kemampuan untuk menendalikan diri adalah sebagai berikut:

“Aku tidak mau kalah. Aku siap meluncurkan serangan balasan yang tidak kalah pedas. Aku buka mulut dan kata-kata panas itu sudah siap aku tembakan dari ujung lidah. Tapi aku hela nafas, aku timbang-timbang lagi, dan akhirnya aku batalkan. “(R3W/2011/169)

Data kutipan yang ada dalam nilai pendidikan moral yang memiliki kedisiplinan adalah sebagai berikut:

"Berani-beraninya kau ya. Sampai bawa-bawa nabi segala. Ayo kita coba. Kalau kau benarbenar serius, datang ke kos aku besok pagi jam 8. Bawa satu tulisan 5 halaman dengan spasi 2. Tidak boleh terlambat sedetik pun." Matanya tajam menikamku. Aku menunduk. Belum belajar kok sudah dapat tugas?" (R3W/2011/68)

Data kutipan yang ada dalam nilai pendidikan moral yang memiliki kejujuran adalah sebagai berikut:

"Joki? Aku menggeleng keras untuk perjokian. Apa gunanya ajaran Amak dan Pondok Madani tentang kejujuran dan keikhlasan?” (R3W/2011/8)

Data kutipan yang ada dalam nilai pendidikan moral yang memiliki rasa tanggungjawab adalah sebagai berikut:

"Aku menduga keras, Ayah telah melego bebeknya, harta paling berharganya, demi membiayai kuliah anak bujangnya. Padahal bukan aku saja beban mereka. Dua adikku sekarang sudah di SMP dan SMA, dan mereka tentu perlu biaya juga. Ini membuat hatiku galau." (R3W/2011/39) 10. 11. 12. "Fokus sajalah kuliah, jangan pikirkan biaya. Urusan itu biar Amak yang memikirkan. Kalau perlu Amak cari pinjaman sampai ujung kampung di tepi danau itu," bisik Amak ke pangkal telingaku ketika aku mencium tangan beliau." (R3W/2011/ 99) "Dengan semangat melonjak-lonjak, aku selipkan 3 lembar uang Rp10.000 bergambar Sultan Hamengku Buwono IX dan Borobudur di tengah lipatan surat untuk Amak. Walau tidak banyak, ini sebuah 
ISSN P 2443-1478

ISSN E 2443-148

prestasi besar dalam hidupku. Ini kali pertama dalam hidupku aku bisa memberi uang hasil keringat sendiri kepada Amak." (R3W/2011/173)

Data kutipan yang ada dalam nilai pendidikan moral yang memiliki kemampuan kreatif adalah sebagai berikut:

"Begitu moderator membuka sesi tanya-jawab, aku mengacungkan tangan tinggi-tinggi, bahkan tidak cukup dengan mengacung, aku sampai berdiri. Melebihkan usaha di atas orang lain, begitu yang aku pelajari di PM dulu. Mungkin bertanya di kala situasi mengantuk adalah caraku untuk bekerja di atas rata-rata teman yang tertidur." (R3W/201/48) "Bang, bagiku Abang seperti nabi Khidir yang punya banyak ilmu, dan aku adalah Musa, aku menyerahkan diri ingin patuh kepada Abang, seperti Musa berguru pada nabi Khidir. Tolonglah aku dipertimbangkan Bang, kataku sungguh-sungguh. Kalau Baso tahu, pasti dia bangga dan senang aku memakai jurusnya." (R3W/2011/67)

Data kutipan yang ada dalam nilai pendidikan moral yang memiliki jiwa nasionalisme adalah sebagai berikut:

"Dengan khidmat dilipatnya bendera ini, diciumnya sekali lagi dan disimpannya di ranselnya. Aku sungguh merasa bersalah. Kawan-kawan lain tidak ada yang berani berkomentar. Lamatlamat aku mendengar pantun lirihnya: Anak kutilang tersesat pagi Ditangkap buyung di atas pagu Walau lima benua aku kelilingi Sang Merah Putih tetap di dadaku" (R3W/2011/234) "Rasa nasionalismeku menjadi terbakar. Dalam hati aku berjanji akan berusaha mendapatkan medali ini, untuk membuktikan bahwa kami anak Indonesia bisa mengalahkan anak-anak Kanada ini. Kalaupun bukan aku yang akan mendapatkan nanti, paling tidak salah satu temanku orang Indonesia. Ini masalah harga diri bangsa, masalah nasionalisme. Indonesia harus dilihat setara sebagai bangsa. Kalau bisa lebih tinggi.” (R3W/2011/287)

Data kutipan yang ada dalam nilai pendidikan moral yang memiliki kemampuan percaya diri adalah sebagai berikut:

"Dengan meyakin-yakinkan diri, aku jawab tantangan ayah. Insya Allah Yah, ambo akan berjuang habis-habisan untuk persamaan ini dan untuk UMPTN.” (R3W/2011/6) 13.

Data kutipan yang ada dalam nilai pendidikan moral yang berprasangka baik adalah sebagai berikut: 
"Kalau mengikuti nasihat Kiai Rais, aku telah menunai-kan semua tugas untuk mencapai keberhasilan. Yaitu niat lurus dan ikhlas, usaha keras, doa khusyuk. Tinggal aku genapi saja dengan huznuzhan, berprasangka baik. Ya Tuhan, aku berprasangka baik untuk semua keputusanMu. Lambat laun, hatiku pun menjadi sejuk dan tenteram.” (R3W/2011/208)

c. Nilai pendidikan Adat/Budaya di dalam novel Ranah 3 Warna karya Ahmad Fuadi.

Data kutipan yang ada dalam nilai pendidikan adat/budaya yang mengarah dalam melestarikan kesenian tradision dan melestarikan budaya berpantun adalah sebagai berikut:

"Di kamarnya yang lapang ada meja belajar, rak buku, dan peralatan alat musik seperti gendang dan talempong serta baju silat Minang yang digantung di balik pintu. Walau di rantau, kecintaan Randai pada seni Minang tetap tidak berubah.” (R3W/2011/45)

"Aku baru tahu kalau orang Kalimantan bisa berpantun. Selama ini aku anggap orang Minang dan Melayu-lah yang punya budaya pantun kuat. Itu pun zaman dulu. Aku sendiri malah tidak pernah berhasil menciptakan pantun dalam hitungan detik. Rusdi hanya terkekeh ketika aku pertanyakan asal kemampuan berpantunnya." (R3W/2011/222) "O, baru tahu ya, kami orang Banjar dulu punya akar budaya berpantun. Bahkan kami punya acara berpantun di TVRI Banjarmasin dengan pembawa acara Jon Tralala. Tapi budaya pantun sekarang mulai punah khususnya di kalangan anak muda. Padahal dulu, bagi sebagian generasi tua, pantun sudah seperti bernafas, sudah refleks. Kapan saja bisa bikin," balas Rusdi. Dia mengaku dalam sepersekian detik pantun bisa dikarang, bahkan sambil dia melantunkan bait awal, dia mengarang bait selanjutnya. Luar biasa. Sejak itu Rusdi aku gelari Kesatria Berpantun.” (R3W/2011/222)

d. Nilai pendidikan sosial (tolong-meno-

long, berbakti pada orangtua, setia kawan, persahabatan, kasih sayang, memberi semangat, dermawan, musyawarah, dan rela berkorban yang ada di dalam novel Ranah 3 Warna karya Ahmad Fuadi.

"Betapa senang hatiku ketika Raisa terkesan dengan pengalamanku menulis di media massa. Lalu dia bilang, "Alif, saya ingin minta bantuan kamu untuk mengajarkan cara menulis yang baik selama kita di Kanada ini. Mau ya?" Hatiku serasa mekar. Tanpa berpikir panjang, aku sanggupi. "Bien sur. Tentu saja. Kapan saja." (R3W/2011/356)

"Dengan senang hati, kami bantu 5 mahasiswi ini memindahkan barang-barang di kamar kos mereka. Bahkan selama beberapa hari mereka sempat menitipkan buku, koper baju, komputer, dan peralatan lain di rumah kami." (R3W/2011:/1)

"Selamat jalan, Ayah. Sampai ketemu nanti di kehidupan setelah mati. 
Selamat jalan, Ayah. Semoga perja-lananmu menyenangkan ke atas sana. Aku akan mendoakan Ayah dari sini. Aku akan mencoba menjadi anak yang saleh yang terus mendoakanmu, supaya menjadi amalmu yang tidak putus. Aku akan mengingat selalu nasihat terakhir Ayah." $(R 3 W / 2011 / 98)$

"Bolehlah badan kurusku ini perih, sakit, bahkan luka, tapi hatiku harus terus besar dan tidak boleh menyerah. Yang aku pertaruhkan di sini adalah kelanjutan kuliahku dan bagaimana bisa bertahan hidup di Bandung. Yang aku kejar di sini adalah bagaimana bisa bahkan mengirimkan uang untuk Amak. Pesan Ayah kembali berputar di kepalaku: "Alif, bela adik-adik dan amakmu. Rajinlah sekolah.” (R3W/2011/117)

"Atau begini saja. Bagaimana kalau gabung saja dengan aku di sini, kita bisa patungan bayar berdua kamar ini." Randai tampaknya kasihan padaku. Dengan senang hati segera aku terima tawarannya. Tawaran ini jelas yang terbaik, jauh lebih murah, dan tempat

kos tidak jauh dari kampusku di Dago Atas. Itulah Randai. Sebagai kawan, dia orang yang setia. Walau di banyak bidang kami bersaing, kami tetap berusaha akur." (R3W/2011/62)

"Kami merubung di sekitar Kak Marwan untuk memutuskan langkah apa

yang harus kami lakukan. Kami jelas tidak bisa meninggalkan Rusdi sendiri. Akhirnya kami memutuskan semua anggota tim Rusdi akan ikut menunggu di Amman selama 3 hari, sedangkan tim lain berangkat lebih dulu." (R3W/2011/251)

"Kami berempat suka berkumpul berganti-ganti dari satu kos ke kos yang lain. Saling berbagi cerita, lawakan, dan rencana-rencana masa depan. Mereka ini mungkin yang akan menjadi saudara-saudara baruku selama kuliah di Bandung.” (R3W/2011/60)

"Rusdi, kayaknya kita harus bersyukur dengan apa yang kita terima sekarang," kataku sok bijak, mengumbar kata-kata penghibur." (R3W/2011/293)

"Ayah sengaja memesan ke tukang sepatu dan terompah di Pasar Ateh. Khusus dari kulit jawi. Asli kulit sapi," kata Ayah sambil membuka kotak itu. Sambil terbatuk-batuk, beliau mengeluarkan sebuah sepatu hitam berkilat-kilat dan mendaratkan ke dekat kakiku." $(R 3 W / 2011 / 40)$

"Setiap hari aku menemani Ayah di bangsal kelas ekonomi ini. Bercerita hilir mudik mulai dari masalah kuliah sampai politik, membacakan kepala berita Haluan dan Singgalang, membahas keunikan rasa durian dari setiap kampung, memijiti kaki dan punggung yang biasanya berakhir dengan ayah terlelap pulas. Kalau waktu makan, sesendok-sesendok aku suapi bubur ke mulutnya. Awalnya ayah menolak, tapi setelah dua suap dia sangat menikmati. Pipinya yang cekung sampai berkecipak-kecipak setiap aku ulurkan sesendok nasi. Begitu terus aku lakukan selama seminggu." (R3W/2011/92) 
"Mado, perempuan berambut pirang yang lembut hati ini selalu telaten membakar roti omelet yang gurih buat sarapanku. Sering dia berlari-lari

tiba-tiba menyusulku yang sudah naik ke sedel sepeda, hanya untuk memasukkan lagi sebungkus biskuit atau sebiji apel ke atas punggungku. Mado bahkan sudah hapal jadwal salatku. Dan sering mengingatkan saat waktu datang agar aku menunaikan salat. Sedangkan Ferdinand banyak berbuat daripada bicara. Aku pernah bilang harus mengirim artikel setiap minggu ke koran di Bandung. Diam-diam dia menghubungi anak sulungnya, Jeaninne yang sudah bekerja di Quebec City, menanyakan apakah punya komputer yang tidak dipakai. Sungguh ajaib, besoknya di meja kamarku sudah duduk dengan manis sebuah komputer Machintosh Classic." (R3W/2011/428)

"Coba kau lihat. Berapa pun mereka berusaha keras, kemungkinan besar mereka tetap jadi orang miskin. Begitu juga anak keturunan mereka nanti. Begitu seterusnya. Sedangkan kau, boleh tidak punya duit, tapi kau ada kesempatan untuk berhasil, bahkan membantu orang seperti mereka. Mereka tidak punya akses untuk pendidikan, kau punya. Jadi kenapa

malas? Kau orang yang beruntung. Tidak pantas kau malas!” katanya berapi-api menunjuknunjuk hidungku. (R3W/2011/162)

"Sore itu, aku datangi sebuah panti asuhan di Jalan Nilem. Aku kais-kais lembar terakhir isi dompetku dan aku serahkan ke bapak pengurus panti. Dia tersenyum sejuk, lalu menyalamiku lama sekali. Matanya terpejam sambil khusyuk mendoakan aku. Aku merinding didoakan seperti itu hanya karena menyumbang 7 ribu rupiah.” (R3W/2011/155)

"Anak-anak ini dengan senang hati mengiringi ke mana pun kami berjalan. Bang Togar bertanya tentang pelajaran sekolah mereka. "Sebentar, Om punya hadiah buat kalian!" serunya. Dia kembali ke mobil dan membawa keluar sebuah kardus yang berisi aneka macam penganan dan memberikannya kepada mereka. Setelah berterima kasih, anak-anak itu bubar, berlari membawa makanan itu ke rumah seng dan tripleks mereka." (R3/2011/160)

"Dalam rangka menyelamatkan mental Rusdi yang rusuh, aku mengundang semua anak Indonesia berkumpul di Café Quebecois di Rue

Saint-Joseph hari Sabtu menjelang siang. Mungkin dengan ramai-ramai

begini, Rusdi bisa terhibur. Dan siapa tahu kami bisa sekalian mencari

solusi untuk nasib Rusdi.” (R3W/2011/327)

"Tahu-tahu, berbagai ide deras berloncatan keluar dari kiri-kanan. Kami tidak jadi beranjak pulang dan berdiskusi tentang apa aja yang bisa kami lakukan untuk acara ini." (R3W/2011/ 392)

"Ada hal yang lebih tepat dikatakan dengan bahasa hati, tahu sama tahu. Aku sayang, aku berutang, dan aku mencintai mereka. Mereka jiwa yang senang tapi mungkin badan yang letih. 
Aku menduga keras, Ayah telah melego bebeknya, harta paling berharganya, demi membiayai kuliah anak bujangnya. Padahal bukan aku saja beban mereka. Dua adikku sekarang sudah di SMP dan SMA, dan mereka tentu perlu biaya juga. Ini membuat hatiku galau." $(R 3 W / 2011 / 39)$

"Apa gunanya masa muda kalau tidak untuk memper-juangkan cita-cita besar dan membalas budi orang tua? Biarlah tulang mudaku remuk dan badanku susut. Aku ikhlas mengorbankan masa muda yang indah seperti yang dinikmati kawan-kawanku." (R3W/2011/117)

\section{PENUTUP}

\section{Simpulan}

Nilai pendidikan yang terdapat dalam novel Ranah 3 Warna karya Ahmad Fuadi meliputi empat wujud nilai pendidikan. Nilai pendidikan agama meliputi beribadah, berdoa, bersyukur, tawakal, ikhlas, dan sabar.

Nilai pendidikan moral meliputi tekad kuat, pantang menyerah, sungguhsungguh, rajin belajar, kerja keras, mampu mengendalikan diri, disiplin, jujur, tanggung jawab, kreatif, nasionalisme, percaya diri, dan prasangka baik. Nilai pendidikan adat/budaya meliputi melestarikan kesenian tradisional dan melestarikan budaya berpantun. Nilai pendidikan sosial meliputi tolong-menolong, berbakti kepada orang tua, setia kawan,

persahabatan, kasih sayang, memberi semangat, dermawan, musyawarah, dan rela berkorban.

Pesan yang disampaikan dalam novel Ranah 3 Warna karya Ahmad Fuadi, adalah:

a. Hubungan manusia dengan Tuhan, meliputi beribadah, berdoa, bersyukur, dan menjalankan puasa sunah.

b. Hubungan manusia dengan diri sendiri, meliputi percaya diri, kerja keras, sabar, selalu berusaha, ikhlas, tanggung jawab, memiliki impian, memiliki rasa nasionalisme, tidak mudah menyerah, kreatif, dan mampu mengendalikan diri.

c. Hubungan manusia dengan manusia lain, meliputi berbakti kepada orang tua, tepat janji, memberi pendidikan, persahabatan, dermawan, kasih sayang, memberi nasihat, dan tolong menolong.

d. Hubungan manusia dengan lingkungan alam, meliputi memuji keindahan alam. Nilai moral dalam novel Ranah 3 Warna karya Ahmad Fuadi tersebut tidak bersifat menggurui dan memenuhi syarat untuk dijadikan bahan pembelajaran karena banyak mengandung nilai-nilai moral yang dapat kita jadikan contoh. 
Jurnal Pujangga Volume 6, Nomor 2, Desember 2020

ISSN P 2443-1478

ISSN E 2443-148

$e$. Berbuat dengan kesungguhan dan kesabaran dalam memper-juangkan cita-cita dan impian. Bagaimana sebuah mimpi dan keinginan wajib diperjuangkan, meskipun hidup penuh dengan ujian dan cobaan yang datang silih berganti. Tuhan sungguh bersama orang yang sabar.Man shabara zhafira, "mantra" yang terdapat didalam novel ini. 


\section{DAFTAR PUSTAKA}

Arikunto, Suharsimi. 2006. Dasar- Dasar Evaluasi Pendidikan. Jakarta: Bumi Aksara. . 2006. Prosedur Penelitian Suatu Pendekatan Praktik. Jakarta: Rineka Cipta.

Bertens, K. 2011. Etika. Jakarta: Gramedia Pustaka Tama.

Depdikbud. 2008. Kamus Besar Bahasa Indonesia. Jakarta: Gramedia Pustaka.

Kohlberg, L. 1964. Development of moral character and moral ideology. Dalam William Crain (Eds.). Theories of Development, Concepts and Applications Third Edition. New Jersey: Prentice Hall. Englewood Cliffs.

Muntolib. 2010. "Aspek Edukatif dan Religius Kumpulan Cerpen Gres Karya Putu Wijaya dan Kaitan-nya dengan Pembelajaran Sastra di SMA". Skripsi, tidak diter-bitkan. Universitas Muhamma-diyah Purworejo, Purworejo.

Nurgiyantoro, Burhan. 2010. Teori Pengkajian Fiksi. Yogyakarta: Gadjah Mada University Press.

Notonegoro. 1962. Pancasila Dasar Falsafah Negara. Jakarta: Bhina Aksara.

Ratna, Nyoman Kutha. 2009. Stlistika Kajian Puitika Bahasa, Sastra, dan Budaya. Yogyakarta: Pustaka Pelajar.

Rindjin, K. 2012. Pendidikan pancasila untuk perguruan tinggi. Jakarta: PT Gramedia Pustaka Utama.

Sumarjo, J. 1986. Apresiasi kesusastraan. Jakarta: Gramedia.

Santosa, Wijaya Heru dan Sri Wahyuningtyas. (2010). Pengantar Apresiasi Prosa. Surakarta: Yuma Pustaka.

Zuhroh, Siti. 2010. "Nilai-Nilai Pendidikan Novel Para Priyayi Karya Umar Kayam". Skripsi, tidak diterbitkan. Universitas Muhammadiyah Purworejo, Purworejo. 